\title{
Editorial
}

\section{“La Asociación Mexicana de Mastozoología, A. C., Nuestra querida AMMAC", Palabras dichas en conmemoración de los 30 años de la AMMAC, el 31 de Octubre de 2014.}

Según Ramírez-Pulido y Britton (1981) la mastozoología en México tiene sus orígenes como disciplina durante el siglo pasado. Yo digo que mucho antes, con comienzos inciertos, empieza a tener claridad con el naturalista Alfred Auguste Delsescautz Dugués (que viene siendo mi tatarabuelo por adopción de mi bisabuela) que de Francia llega a México en 1853 y muere en Enero de 1910 además de su trabajo como médico en las minas en Guanajuato se dedicaba a explorar y describir la fauna del centro de México, con viajes tan increíbles como ir de la planicie costera de Veracruz a Querétaro y Guanajuato en mulas, describiendo la fauna.

Después otro naturalista que ha pasado un tanto desapercibido por sus aportaciones fue Fernando Ferrari-Pérez expedicionario y colector-naturalista de la Comisión Geográfico Exploradora desde 1880; en 1909 se crea la Sección de Historia Natural de esta comisión, que entre sus deberes tenían el oficio de colectar y realizar un estudio integral de la fauna y la flora de México. Las aportaciones de Ferrari-Pérez al Museo de Historia Natural cuando estaba en El Chopo, son impresionantes; entre su haberes, participó en expediciones a Cayos triángulos en Campeche a colectar ejemplares vivos y preparados de la extinta foca monje del Caribe. No se sabe mucho de él pero sin duda habrá que escarbar un poquito más para conocer otras aportaciones.

Volviendo a Ramírez-Pulido y Britton, ellos presentan cuatro períodos que caracterizan el desarrollo de la mastozoología en México:

El 1º de 1831 a 1881 destacando Henri Saussure y Spencer Fullerton Baird. Aquí incluiríamos a Alfredo Dugués.

El $2^{\circ}$ de 1887 a 1919 en el que comienzan con C. Hart Merriam. Aquí incluiríamos a Ferrari-Pérez; y termina al iniciarse la Revolución Mexicana.

El $3^{\text {er }}$ periodo de 1922 hasta 1942 en que después de la Revolución se renueva el interés por los estudios en México, E.W. Nelson y E. A. Goldman describen el $52 \%$ de los taxa mexicanos, es en este periodo cuando empieza a nacer la mastozoología en México con los primeros trabajos de Bernardo Villa-Ramírez.

El $4^{\circ}$ periodo es un tiempo de síntesis y en él destacan de 1943 a 1980. Con la presencia de L. M. Huey, G. G. Goodwin, B. Villa-Ramírez, T. Álvarez, W. Dalquest, C. Hubbs, R. Hall. M. Álvarez del Toro, J. Ramírez-Pulido, K. S. Norris, W. López-Forment, G. Urbano, W. F. Perrin, C. Sánchez-H., Jiménez, B. Le Boeuf y otros más. 
Aquí podemos añadir un $5^{\circ}$ periodo, el contemporáneo, desde 1980, en el que se ha venido incrementando el número de jóvenes, biólogos, ingenieros forestales, agrónomos y veterinarios interesados en conocer la fauna mastozoológica del país, y que han venido haciendo nuevos estudios en taxonomía, ecología, comportamiento, distribución, así como también se ha denunciado y testificado impotentemente la desaparición de algunas de ellas.

Dentro de este periodo, la influencia de la AMMAC comienza en 1982, en el VI Congreso Nacional de Zoología en Mazatlán, en donde se anuncia por primera vez la intención de conformar la Sociedad Mexicana de Mastozoología.

En 1983 un grupo de estudiantes coincidimos por azares del destino en el Laboratorio de Mastozoología del Instituto de Biología, algunos con intereses en murciélagos, otros en roedores, otros en mamíferos acuáticos, unos más en ecología, otros en taxonomía, o en paleontología; formamos una red de conocidos que finalmente formó una masa crítica. Éramos egresados de la Facultad de Ciencias de la UNAM, de la UAM (Universidad Autónoma metropolitana) Iztapalapa y Xochimilco, del INAH (Instituto Nacional de Antropología e Historia) y de otras universidades, así nos juntamos: Alondra Castro, Esther Romo, Livia León, María Canela, Rosario Manzanos, Silvia Manzanilla; Álvaro Miranda, Federico Romero, Héctor Arita, Hiram Barrios, Juan Carlos Morales, Juan Pablo Gallo, Rodrigo Medellín; algunos todavía estudiantes, otros ya egresados, algunos estaban en el posgrado en el extranjero como Daniel Navarro, Fernando Cervantes, Gerardo Ceballos y Víctor SánchezCordero; otros cursando el posgrado en la facultad de Ciencias. De todos nosotros surgió la propuesta en firme de ir adelante, de fundar la Asociación Mexicana de Mastozoología, ¿por qué no?

Nos juntábamos, teníamos pláticas iniciales, discusiones, dudas, miedos, interrogantes, propuestas de los estatutos, votaciones y después a averiguar ¿cómo se le hacía para conformar una Asociación?, salíamos en grupo a visitar a otras asociaciones como FAUNAM y SOMEMMA; nos decían todos los pasos que había que hacer para lograrlo, que había que registrar el nombre en Relaciones Exteriores para ver si el nombre no estaba ya registrado en algún otro lugar del mundo, después a la Secretaría de Hacienda; tuvimos que cambiar de Notaria, cambiamos a la Notaría No. 58 en Bucareli. Se hicieron viajes a Mazatlán y a Xalapa a los Congresos de Zoología a volantear he inscribir a personas interesadas en la AMMAC les caímos a los colegas para pasar de "invitados" la noche en el suelo de sus habitaciones de hotel, vender camisetas, vender camisetas y proyectar videos. Así en el primer año teníamos una buena lista de personas interesadas en la Asociación iy eso que no había correo electrónico!

Traíamos un dinamismo que comenzaba a molestar a los investigadores del Instituto de Biología por la ocupación de casi todo el Laboratorio de Mastozoología del Instituto, así que ante la suspicacia de lo que estábamos haciendo y de que los investigadores se preguntaban ¿para qué quieren hacer esto?, nos corrieron del Instituto de Biología (hay que agradecer públicamente a Guille Urbano y Oscar Sánchez que nos mantuvieron ahí por las tardes, y no nos olvidemos de Raúl Martínez "El Trac", que siempre ha sido nuestro cómplice y nos abría el laboratorio a donde nos colábamos a hurtadillas), pero llega la noticia en definitiva en un comunicado del departamento de Zoología del Instituto diciendo que no podíamos seguir haciendo reuniones ahí, entonces comenzamos a juntarnos, primero, 
afuera en los patios y jardines del Instituto de Biología, después en las casas, la de Rodrigo Medellín (que por muchos años fungiría como la Dirección Oficial de la AMMAC), en la de Silvia Manzanilla, en la mía o en el Museo de Zoología de la Facultad de Ciencias. Finalmente, acudimos a Pepe Ramírez Pulido (a quién hay que agradecer mucho su apoyo por creer en nosotros desde un inicio), varias veces nos invitó a un rico restaurante por los rumbos de Iztapalapa y comíamos con él, nos orientó y nos dejó hacer; nos dio el impulso final; no importaba, teníamos ya un objetivo muy claro y era fundar una asociación con la finalidad de: Promover el desarrollo de la mastozoología en México. Con los siguientes objetivos (y leo de los Estatutos. Capítulo II: Finalidad. Artículo Tercero):

Estudiar y proponer soluciones conjuntas a problemas y políticas de manejo y conservación de los recursos naturales en México, particularmente de los mamíferos.

Reunir a todas las personas interesadas en mamíferos en México,

Promover y organizar la interacción entre personas y grupos interesados en la Mastozoología en México,

Difundir y estimular las actividades relacionadas con la Mastozoología en México, a través de:

Organizar reuniones y asambleas periódicas (ordinarias y extraordinarias), atendiendo a un programa adecuado de trabajo y a las cuales asistirán los miembros que las constituyan.

Formular programas con objeto de llevar a cabo una labor coordinada de estudio e investigación.

Organizar conferencias o ciclos de éstas sobre mastozoología y ciencias afines.

Mantener un constante intercambio con todas las instituciones que se interesen por la mastozoología en la República Mexicana y en el extranjero y con los investigadores y estudiosos de éstas disciplinas.

Publicar periódicamente un órgano de divulgación científica de las ciencias mastozoológicas y afines.

Iniciar un programa de relaciones con el mayor número de editoriales para obtener la formación de la biblioteca y Hemeroteca de la Asociación.

Mediante los resultados obtenidos por los estudios que se proponen en el primer objetivo de la Asociación, sugerir soluciones a quienes tienen a su cargo la planeación, coordinación y ejecución de las decisiones sobre problemas específicos que conciernan a la fauna mastozoológica de México.

La posibilidad de adquirir o poseer los bienes muebles e inmuebles que sean necesarios, previos los permisos correspondientes.

Además de todo esto, queríamos ser como la American Association of Mammalogists que todos admirábamos por su capacidad de lograr congresos muy enriquecedores e interesantes y por la difusión del conocimiento universal de estos conocimientos en el Journal of Mammalogy. 
Primero pusimos los pocos fondos personales que teníamos, después vendimos camisetas, miles de ellas en la Facultad de Ciencias, en el Instituto de Biología y en varios congresos; pero ya no podíamos seguir juntándonos fuera de alguna institución que nos cobijara el momento nos pedía avanzar hacia otra etapa. Así que poco tiempo después informé al Dr. Villa que por común acuerdo de todos los miembros (fundadores) de la AMMAC queríamos nombrarlo Presidente Honorario Vitalicio de la Asociación; recuerdo gratamente su gran sonrisa ante esta noticia, ¡Vaya, esto nos abrió las puertas de nuevo al Instituto!, así volvimos, con la salvedad de que sólo podíamos reunirnos en las tardes, por supuesto sentíamos y confirmábamos que el Laboratorio de Mastozoología era Nuestro.

Así, después de muchos vaivenes el 6 de Diciembre de 1983 queda constituida la Primera Mesa Directiva de la AMMAC en la votación en el Instituto de Biología quedando de la siguiente manera:

Presidente Honorario Vitalicio el Dr. Bernardo Villa-Ramírez.

Presidente, Juan Pablo Gallo Reynoso.

Vicepresidente, Daniel Navarro López.

Tesorera, María Canela Rojo.

Secretario, Rodrigo Medellín Legorreta.

Vocales.

Investigación, Silvia Manzanilla Naim, Livia León Paniagua, Juan Carlos Morales, Gerardo Ceballos y Víctor Sánchez-Cordero.

Difusión, Héctor Arita Watanabe y Fernando Cervantes.

Acervo, Hiram Barrios, Rodrigo Medellín y Álvaro Miranda.

Administración, Rosario Manzanos y Alondra Castro.

Corrían los primeros meses de 1984 y se seguían discutiendo y afinando los estatutos de la Asociación y ante el Notario Público No 58 Mario Daniel Reynoso Obregón (mi Tío por parte de mi madre y padrino de bautizo), el 16 de marzo se firma el Acta Constitutiva que da vida legal a la Asociación Mexicana de Mastozoología, A. C. Al fin de ese año, para el 22 de Diciembre de 1984 la AMMAC contaba con un ingreso de cuotas y donativos por $\$ 44,310.00$ (viejos pesos) que se comenzaron a usar en la papelería y la difusión de un primer boletín, previo al honroso "Zacatuche".

Para finalizar quiero decir que hace 30 años éramos un conjunto de jóvenes que queríamos hacer algo por conocer más sobre los mamíferos de México, no sabíamos muy bien qué o cómo hacerlo, pero pusimos nuestro empeño en vernos como una sociedad activa, que hoy en día, la opinión de sus miembros asociados ha sido y es muy importante en la toma de decisiones a nivel de nuestro país sobre la conservación, las áreas naturales protegidas y el conocimiento de los mamíferos de México, tanto a nivel nacional como internacional. Solo hay que ver cuántos jóvenes acuden a los Congresos Nacionales de Mastozoología en donde conviven investigadores y estudiantes de todas partes de México, para volver a inspirarse. 
Hoy en día se ha logrado esto, somos una asociación viva, muy dinámica, estamos presentes en todo el país; no solo eso, tenemos también nuestra revista "Therya" y un gran compromiso a futuro con la sociedad y con la fauna mastozoológica; así que quisiera decir "Misión cumplida viejo", pero no, lo mejor está por venir...

Felicidades a la AMMAC y a todos los miembros que han dedicado su tiempo y que han fungido en las respectivas mesas directivas de estos 30 años.

¡Gracias!

\section{Juan-Pablo Gallo-Reynoso.}

Centro de Investigación en Alimentación y Desarrollo, A.C., Unidad Guaymas. Carretera al Varadero Nacional km 6.6. Guaymas 85480, Sonora, México. E-mail jpgallo@ciad.mx

\section{Literatura citada}

Ramírez-Pulido, J., y M. C. Britton. 1981. An historical synthesis of the Mexican mammalian taxonomy. Proceedings of the Biological Society of Washington 91:1-17. 
EDITORIAL

700 THERYA Vol.5(3):695-699 